\title{
Perancangan dan Analisa Karakteristik Traksi Sistem Powertrain Mobil Produksi Pedesaan
}

\author{
Muhammad Sukma Wirayudha Sunggono dan Unggul Wasiwitono \\ Laboratorium Desain Otomotif Teknik Mesin, Fakultas Teknologi Industri, \\ Institut Teknologi Sepuluh Nopember (ITS) \\ Jl. Arief Rahman Hakim, Surabaya 60111 Indonesia \\ e-mail: unggul@me.its.ac.id
}

\begin{abstract}
Abstrak - Mobil Produksi Pedesaan dirancang untuk dioperasikan diwilayah pedesaan yang tentunya memiliki medan jalan lebih beragam daripada medan jalan pada umumnya. Medan jalan yang dimaksud seperti tanjakan turunan curam, jalan berbatu, jalan berpasir, jalan yang basah, jalan sempit yang banyak ditemui didaerah perbukitan, pegunungan, dan pesisir pantai.Dalam penelitian ini dilakukan sebuah perancangan dan analisa terhadap komponen Power Train pada Mobil Produksi Pedesaan. Mobil dirancang menggunakan engine Sinjay 2. Perhitungan yang dilakukan meliputi mediasi aliran daya pasa sistem powertrain, memilih rasio - rasio yang ada, penyesuaian karakteristik antara engine dan transmisi. Setelah didapatkan parameter dari powertrain maka selanjutnya dilakukan perancangan layout dan tiap elemen dalam powertrain.Dari hasil penelitian, untuk dapat menempuh medan tanjakan maksimal dan kecepatan maksimal yang diinginkan maka rasio transmisi yang digunakan berturutturut $6.5,4.4,2.8$, dan 2 untuk rasio gigi 1 sampai 4 , sedangkan untuk final drive digunakan rasio bernilai 5. Dengan rasio tersebut Mobil Produksi Pedesaan akan memiliki kemampuan menanjak maksimal gradient jalan $44 \%$ dan akselerasi maksimal $2,8 \mathrm{~m} / \mathrm{s}^{2}$. Penggunaan modifikasi sistem Transfer Case memungkinkan kendaraan untuk memindah daya engine untuk memutar mesin produksi lebih terintegrasi dan dapat beroperasi mode penggerak 4 roda.
\end{abstract}

Kata Kunci-Daya engine, Powertrain, Rasio Transmisi, Daya engine .

\section{PENDAHULUAN}

$\mathrm{M}$ obil Produksi pedesaan dirancang untuk dioperasikan diwilayah pedesaan yang tentunya memiliki medan jalan lebih beragam daripada medan jalan pada umumnya. Medan jalan yang dimaksud seperti tanjakan turunan curam, jalan berbatu, jalan berpasir, jalan yang basah, jalan sempit yang banyak ditemui didaerah perbukitan, pegunungan, dan pesisir pantai. Kondisi demikian membuat Mobil Produksi pedesaan yang telah ada tidak cukup hanya sebagai mobil yang dapat mengangkut sekaligus mengolah hasil pertanian, akan tetapi mobil akan lebih sempurna jika dirancang dapat melewati medan sulit yang ada secara optimal.

Spesifikasi penggunaan engine yang sama mengharuskan pengurangan berat total rancangan mobil yang baru. Hal ini dilakukan untuk meningkatkan performa mobil di medan jalan yang sulit. Kendaraan yang ringan memungkinkan Gaya dorong berlebih yang tersisa lebih besar sehingga kemampuan menanjak dan akselerasi mobil meningkat [1]. Jalan pada umumnya dirancang memiliki gradient maksimal jalan kurang dari $7 \%$ [2], akan tetapi untuk kasus khusus seperti daerah pegunungan pada lokasi Turracher Höhe di Austria gradient kemiringan jalan bisa ditemui hingga $26 \%$ [2]. Pada perancangan ini diharapkan kendaraan mobil Produksi pedesaaan dapat menanjak hingga gradient kemiringan $45 \%$ karena memang kondisi jalan yang masih buruk di daerah pedesaan di Indonesia.

Daerah operasi mobil pada daerah pedesaan membuat factor kebutuhan akan kecepatan yang diinginkan berbeda dengan mobil penumpang pada umumnya. Kendaraan yang dirancang untuk kebutuhan komersial seperti truk biasanya memiliki kecepatan maksimal yang rendah berkisar antara 70 $-80 \mathrm{~km} / \mathrm{jam}$ [4]. Mobil yang dirancang pada tugas akhir ini ditentukan jika kecepatan maksimal yang dapat dibentuk hanya sebesar $80 \mathrm{~km} / \mathrm{jam}$ saja, tentunya dengan kecepatan yang rendah, diharapkan efektifitas dari penggunaan engine yang sama dapat meningkat.

Dalam penelitian ini dilakukan sebuah perancangan dan analisa ulang mobil Produksi pedesaan dari awal menggunakan engine Sinjay 2. Perancangan dilakukan terhadap komponen Power Train pada mobil Produksi pedesaan untuk memaksimalkan komponen Power Train sehingga dapat melalui medan atau jalan daerah terpencil lebih optimal.

\section{SISTEM POWERTRAIN}

Analisa dimulai dengan menghitung kebutuhan gaya traksi dari total gaya hambat angin, gaya whell resintance, gradient resintance, dan acceleration resistance. Lalu dilakukan perhitungan nilai - nilai rasio pada setiap komponen powertrain dengan menggunakan data tanjakan maksimal, kecepatan maksimal yang diinginkan dan batasan dimensi dari chassis referensi mobil. Data rasio yang didapat dan data engine lalu digunakan untuk menghitung daya traksi yang dapat disediakan oleh sistem powertrain. Diagram traksi dapat diperoleh menggabungkan semua data diatas, lalu untuk memperjelas analisa karakteristik traksi juga dibuat diagram performa kendaraan climbing performance dan acceleration performance serta grafik adhesion limit saat mobil berjalan dalam mode $2 \mathrm{WD}$ dan $4 \mathrm{WD}$ untuk menganalisa pengaruh perubahan mode berkendara pada performa kendaraan.

Data rasio dari setiap komponen dan analisa karakteristik traksi powertrain digunakan dalam proses perancangan element machine dari setiap komponen. Standar ANSI/AGMA 2001-D04 dan ANSI/AGMA 2003-B97 digunakan dalam proses perancangan Spur Gear dan Bevel Gear [3]. Maximum Distorsion Enegy Theory, Von Mises, dan $D E$ Goodman digunakan dalam perancangan poros [4]. Perancangan Splines dan pemilihan bearing menggunakan katalog SKF dilakukan.

Data - data yang ada didapat yang dibutuhkan dalam proses perhitungan didapat dari studi lapangan maupun studi literatur, Sedangkan untuk konstanta - konstanta yang diperlukan diambil dari handbook dengan memperhatikan kemiripan bentuk kendaraan, Untuk data kendaraan kinerja 
engine sendiri yang meliputi kecepatan, putaran engine, data daya engine dan torsi engine didapat dari hasil dynotest seperti ditunjukkan pada Gambar 1.

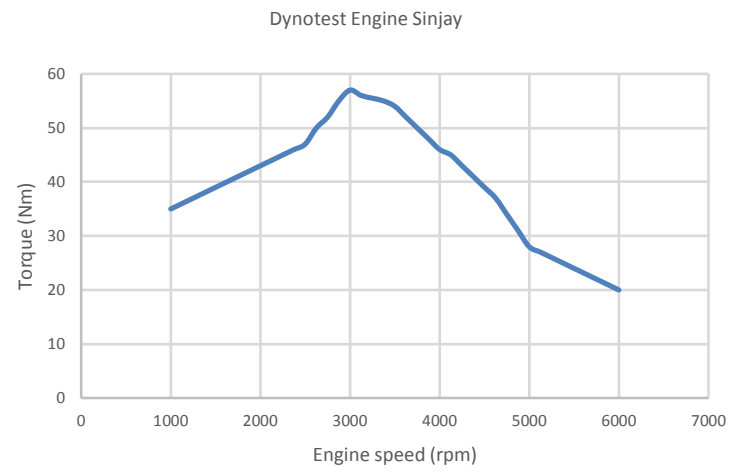

Gambar 1 Grafik Torsi terhadap putaran dynotest Mesin Sinjay[5]

Layout dari rancangan sistem Powertrain tampak pada Gambar 2. Detail dari setiap geometri dan material didapatkan dari data data- data yang sudah dihitung sebelumnya. Visualisai rancangan tiap komponen Powertrain dijelaskan dengan gambar 3 dimensi menggunakan bantuan software CAD.

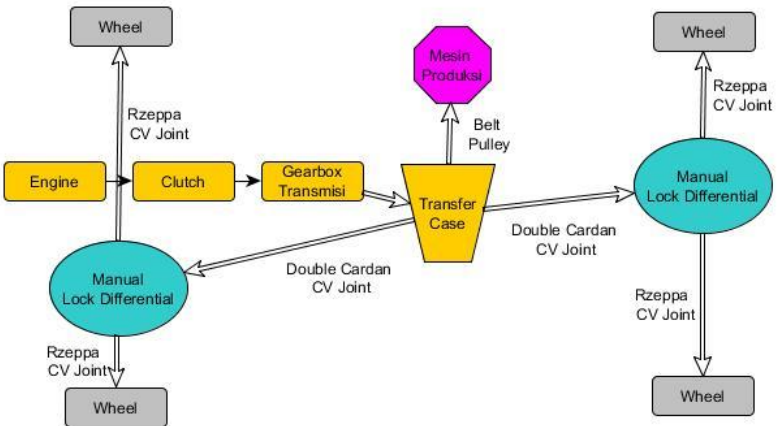

Gambar 2 Skema Mobil Produksi Pedesaan 4WD dengan modifikasi Transfer Case

\section{HASIL DAN ANALISA}

\section{III.1 Memilih Rasio dalam sistem Powertrain.}

Penentuan nilai dan tingkatan dari rasio setiap tingkatan gigi ditentukan menggunakan metode geometrical, dimana rasio terbesar ditentukan dari kemampuan tanjakan maksimal kendaraan yang diinginkan, sedangkan rasio minimal ditentukan dari kecepatan maksimal yang diinginkan. Besar rasio dari final drive dipilih dengan batasan komponen pembuat rasio, pada penelitian ini dipakai bevel gear dengan nilai rasio 5. Tabel 1 menjelaskan nilai rasio dari setiap komponen penyusun Powertrain.

Tabel. 1 Data rasio dari setiap komponen sistem Powertrain

\begin{tabular}{|l|l|c|}
\hline \multirow{4}{*}{$\begin{array}{l}\text { Speed } \\
\text { Ratio }\end{array}$} & First gear & 6.5 \\
\cline { 2 - 3 } & Second Gear & 4.4 \\
\cline { 2 - 3 } & Third Gear & 2.8 \\
\cline { 2 - 3 } & Fourth Gear & 2 \\
\cline { 2 - 3 } & Reverse Gear & 5 \\
\cline { 2 - 3 } & Final Drive & 5 \\
\hline
\end{tabular}

III. 2 Diagram Traksi

Setelah perhitungan Required Traction / $F_{Z, B}$ dan Available Traction / $F_{Z, A}$ dilakukan, maka dapat dilakukan analisa traksi yang terjadi saat kendaraan mobil Produksi pedesaan saat berjalan. Gambar 3 menjelaskan bagaimana perbandingan grafik $F_{Z, B}$ dan $F_{Z, A}$ berbanding dengan kecepatan laju kendaraan. Tampak pada grafik jika kendaraan mampu melaju pada kondisi jalan mendatar (gradient 0\%) hingga kecepatan maksimal $75 \mathrm{~km} / \mathrm{jam}$, hal ini dikarenakan karena terjadi perpotongan antara garis $F_{Z, B}$ dan $F_{Z, A}$ yang mengindikasikan jika Traction Available sudah tidak dapat memenuhi Traction required. Selain itu juga tampak jika nilai $F_{Z, A}$ terbesar pada kondisi tingkat gigi kecepatan ke-1 sudah tidak mampu melawan $F_{Z, B}$ pada kondisi gradient kemiringan jalan $45 \%$. Hal ini menyebabkan Mobil Produksi pedesaan yang dirancang memiliki kapasitas kemampuan maksimal menanjak dengan kemiringan gradient $45 \%$.

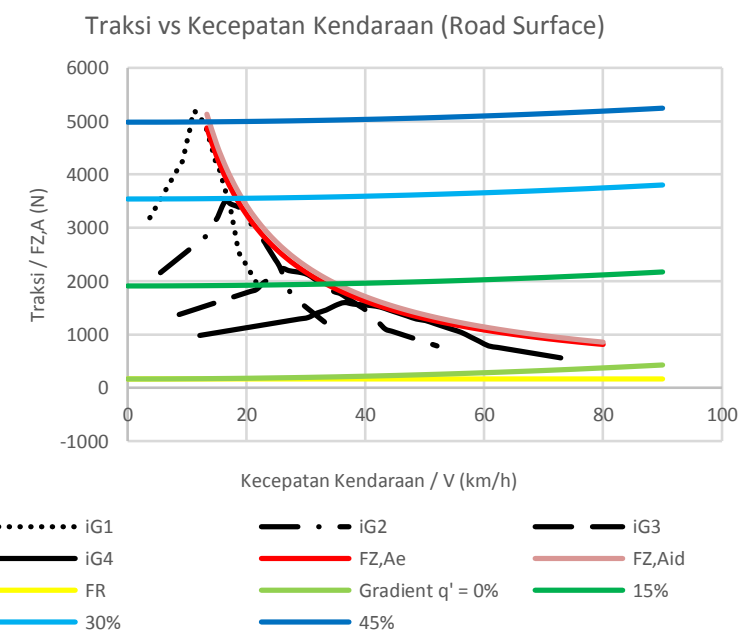

Gambar 3 Grafik Required Traction / $\mathrm{F}_{\mathrm{Z}, \mathrm{B}}$ dan Available Traction / $\mathrm{F}_{\mathrm{Z}, \mathrm{A}}$ Kecepatan

Climbing Performance (Road Surface)

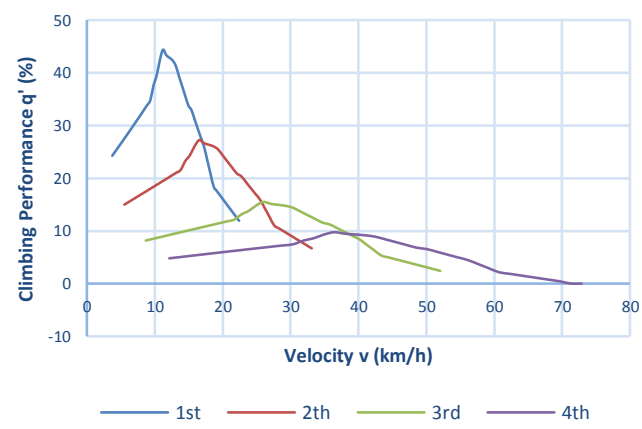

(a)

Acceleration Performance (Road Surface)

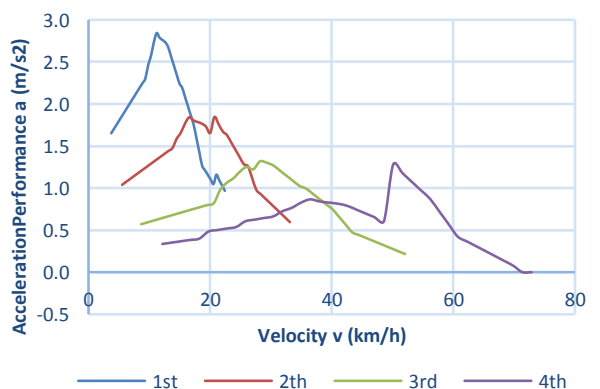

(b)

Gambar 4 Grafik Climbing (a) dan Acceleration Performance (b) pada permukaan aspal 


\section{III.3 Vehicle Performance}

Analisa bagaimana performa kendaraan dapat dilihat dari kemampuan percepatan kendaraan Acceleration Performance dan kemampuan kendaraan untuk menanjak Climbing Performance. Hal ini sangat membantu dalam memperjelas analisa dari Karakteristik Traksi kendaraan. Untuk mendapatkan data performa Kendaraan sebelumnya harus dihitung nilai dari Traksi yang berlebih Excees Traction yang merupakan nilai selisih antara $F_{Z, B}$ dan $F_{Z, A}$.

Gambar 4 menunjukan grafik climbing dan acceleration performance pada permukaan jalan aspal. Tampak pada grafik Climbing Performance mobil Produksi pedesaan rancangan akan mampu menanjak hingga gradient $45 \%$ pada saat mobil dalam kondisi gigi kecepatan ke-1. Dan mobil akan mampu melakukan akselerasi maksimal 2,8 m/s ${ }^{2}$. Pada kondisi jalan tanah atau kerikil terdapat penurunan performa climbing dan acceleration. Mobil hanya akan mampu menanjak maksimal pada gradient kemiringan jalan $30 \%$ dan akselerasi maksimal $2 \mathrm{~m} / \mathrm{s}^{2}$, saat kondisi tingkat gigi kecepatan ke-4 Mobil sudah tidak dapat melaju pada medan tanjakan dan sudah tidak dapat melakukan akselerasi.

\section{III.4 Adhesion Limit}

Bagaimana detail pengaruh mode 4WD dalam meningkatkan performa mobil dapat dilihat pada Gambar 5. Tampak pada gambar 5 saat mode 2WD kontur permukaan jalan aspal nilai Adhesion Limit sangat jauh berada diatas grafik traksi kendaraan sehingga saat melaju di jalan aspal Mobil akan aman tidak mengalami slip pada ban.

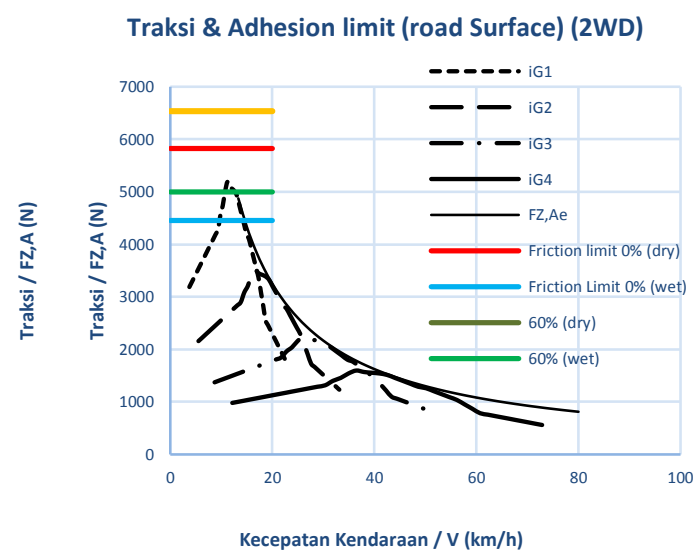

(a)

Traksi \& Adhesion limit (road Surface) (4WD)

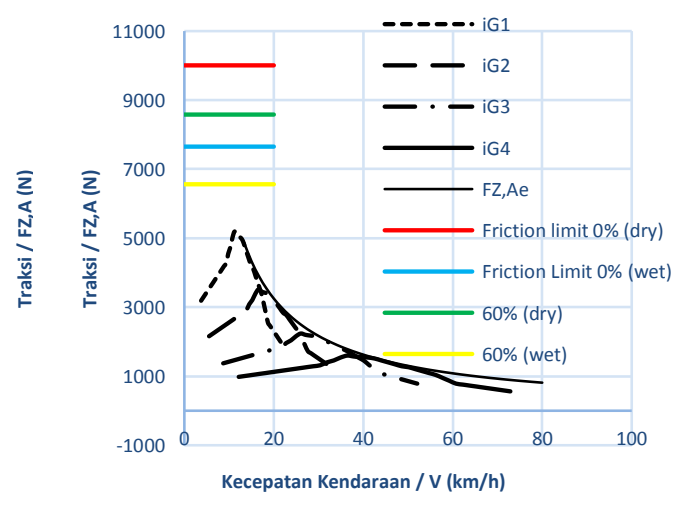

(b)

Gambar 5 Grafik Adhision Limit 2WD (a) dan $4 W D$ pada permukaan aspal (b)
Kondisi akan berbeda saat mobil melaju pada permukaan tanah, Saat kondisi jalan tanah kerikil basah atau terdapat kemiriangan nilai Traksi mobil berada diatas nilai Adhesion Limit sehingga Mobil akan kehilangan gaya dorong karena roda mengalami slip, pada kondisi ini mobil harus memulai start jalan pada gigi kecepatan ke-2 untuk menurunkan Torsi. Pada kondisi tanah lumpur atau pasir mobil sudah tidak bisa lagi berjalan akibat slip yang terjadi karena hampir keseluruhan traksi dorong yang dihasilkan berada diatas Adhesion Limit.

\section{III.5. Sistem Transmisi}

Detail rancangan dari sistem transmisi geometri dan layout dapat dilihat pada Gambar 6. Sistem transmisi terdiri 4 tingkat dan gigi mundur. Tipe dari transmisi adalah 2 stage. Dan menggunakan sistem synchromesh untuk memperhalus proses perpindahan gigi.

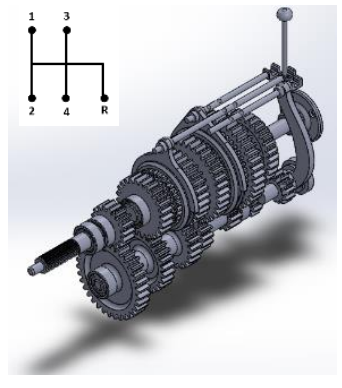

(a)

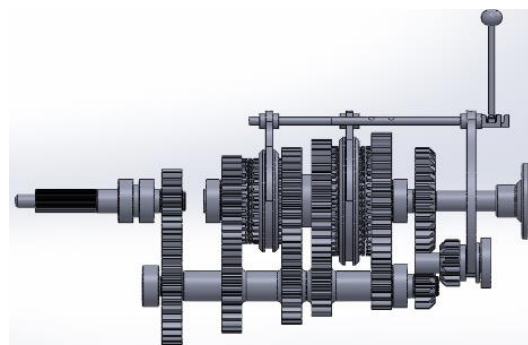

(b)
Gambar 6 Rancangan sistem transmission Mobil Produksi Pedesaan baru, dengan 4 tingkat kecepatan dan gigi mundur tampak isometric (a) dan tampak samping (b).

\section{III.6. Sistem Transfer Case}

Detail rancangan dari sitem transfer case dapat dilihat pada gambar 7. Rancangan memiliki 2 buah tuas. Tuas pertama untuk memindahkan saat mode berkendara atau saat mode produksi. Dan tuas kedua berfungsi untuk merubah mode kendaraan 2WD dan 4WD. Sistem transfercase tidak menggunakan syncromesh sehingga setiap ingin dilakukan perpindahan mode maka mobil haris dalam kondisi berhenti.

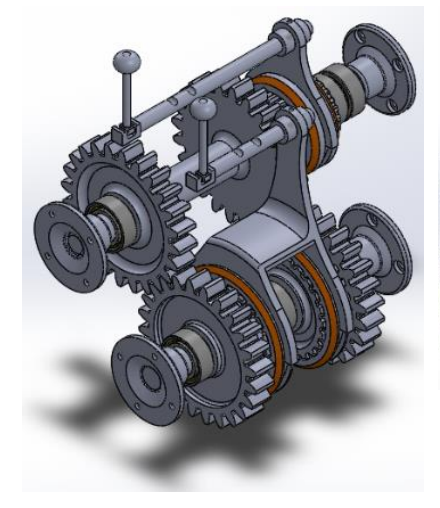

(a)

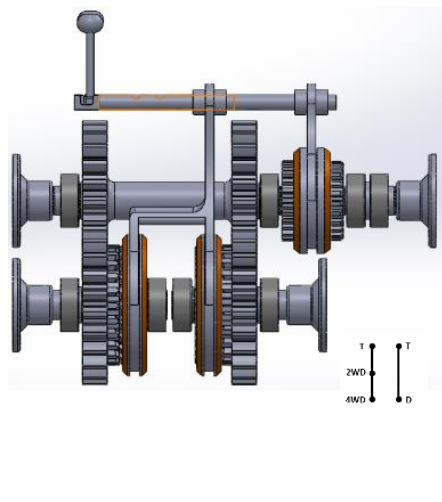

(b)
Gambar 7 Sistem Transfer Case Mobil Produksi Pedesaan tampak Isometric (a) dan tampak samping (b), Mode operasi 2WD, $4 W D$, dan Mesin Produksi.

\section{III.7. Sistem Manual Lock Differential.}

Detail sistem rancangan Manual Lock Differential dapat dilihat pada Gambar 8. Pasangan pinion-bevel membentuk rasio final drive dengan nilai 5. Sistem differential berfungsi untuk mengadaptasi kecepatan putaran roda dalam dan luar saat berbelok. Tambahan fitur manual lock berfungsi sebagai 
solusi saat mobil berkendara pada kondisi jalan yang memiliki adhesion limit yang sangat rendah seperti lumpur dan pasir. Sehingga Torsi yang diberikan pada kedua sisi roda akan berbeda beradaptasi dengan kondisi jalan.

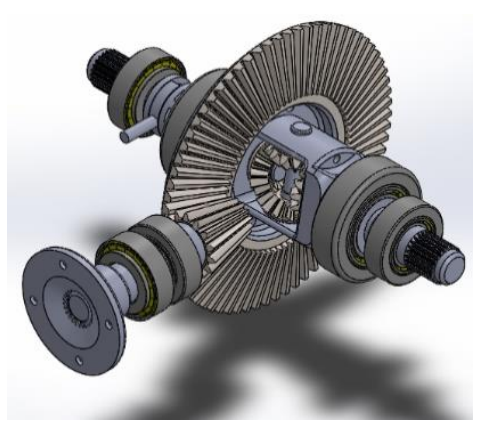

Gambar 8 Rancangan sistem Manual Lock Differential tampak Isometric

\section{III.8 Layout Mobil Mutliguna Pedesaan}

Layout dari keseluruhan Mobil Produksi Pedesaan tamapak pada Gambar 9. Mesin produksi akan diletakkan pada bagian belakang mobil dengan penyambung daya dari transfercase menggunakan belt-pulley. Mobil dirancang dengan kapasitas angkut 2 penumpang. Tampak adaptasi dari komponen chassis mobil dengan harapan perancangan komponen - komponen pelengkap lainnya akan dapat lebih mudah mengadaptasi kebutuhan performa mobil untuk dapat beroperasi pada medan sulit lebih handal.

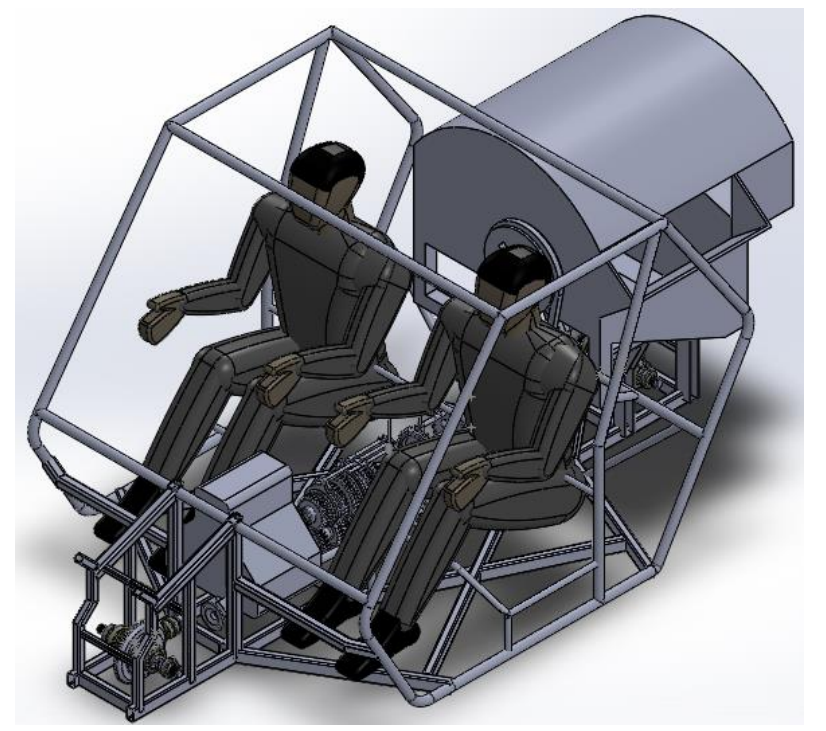

(a)

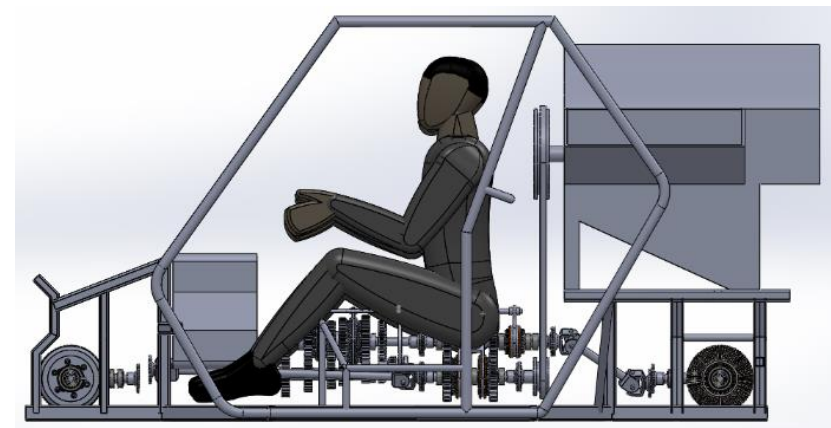

(b)

Gambar 9 Keseluruhan rancangan Mobil Produksi Pedesaan tampak Isometric (a) dan tampak samping (b).

\section{KESIMPULAN}

Setelah melakukan analisa perhitungan dan pembahasan didapatkan kesimpulan sebagai berikut:

1. Spesifikasi rancangan ulang nilai rasio yang terdapat pada sistem Powertrain adalah rasio pada sistem Transmisi dan Final Drive dengan nilai rasio yang telah ditentukan.

2. Karakteristik Traksi dengan sistem Powertrain yang ada menunjukkan Traksi maksimal pada setiap kecepatan gigi terhitung pada data.

3. Kecepatan maksimal, Acceleration Performance, dan Climbing Performance yang dapat dilakukan oleh mobil saat berjalan pada permukaan aspal, tanah, dan lumpur terhitung pada data.

4. Adhesion Limit saat mode berkendara penggerak 4 roda dan 2 roda terhitung pada data.

5. Geometri dan Material dari komponen Spur Gear, Bevel Bevel, Poros, Splines, dan Bearing dapat dilihat pada gambar assembly.

\section{DAFTAR PUSTAKA}

[1] Sutantra, I Nyoman \& Bambang Sampurno. 2010. “Teknologi Otomotif : Edisi Kedua". Surabaya: Guna Widya.

[2] Harald Naunheimer,Bernd Bertsche, Joachim Ryborz, Wolfgang Novak. 2011 "Automotive Transmission, second edition". Springer.

[3] Shigley's, Richard G. Budynas \& J Keith Nisbeth. 2011 "Shigley's Mechanical Engineering Design, ninth edition". McGraw-Hill series in Mechanical Engineering.

[4] D. Deutchman, aarom, Walter J.Michels \& Charles E. Wilson. 1975. "Machine Design". New York Macmillan Publishing Co., Inc.

[5] Pramono, Agus Sigit. 2014. "Rancang Bangun Kendaraan Produksi Pedesaan”. Insentif Riset SINas LPPM ITS. 